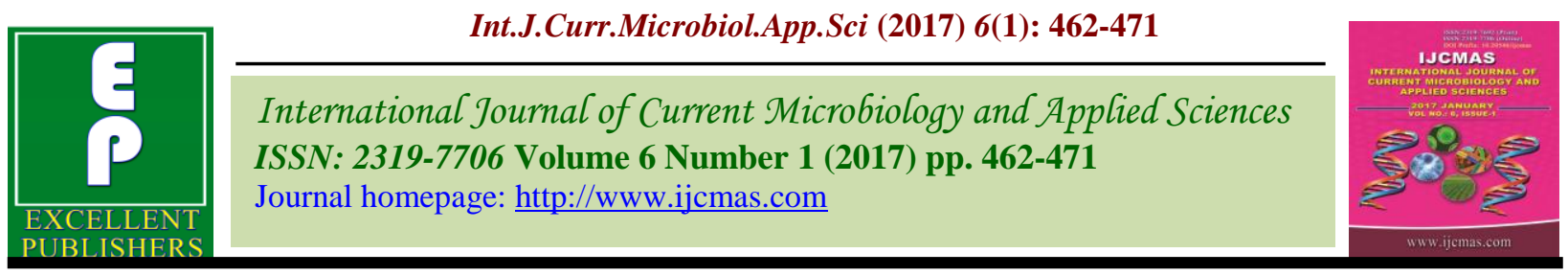

Original Research Article

http://dx.doi.org/10.20546/ijcmas.2017.601.054

\title{
Mapping of Quantitative Trait Loci (QTL) for Na+ and K+ Uptake Controlling Rice Salt Tolerance (Oryza sativa $L$.)
}

\author{
Aysam M. Fayed ${ }^{1}$ and Mona A. Farid ${ }^{2 *}$ \\ ${ }^{1}$ Molecular Biology Department, Genetic Engineering and Biotechnology Research Institute, \\ University of Sadat City, Egypt \\ ${ }^{2}$ Genetics Department, Faculty of Agric., KafrElshikh University, Egypt \\ *Corresponding author
}

\begin{tabular}{|c|c|}
\hline & A B S T R A C T \\
\hline & An F2 population derived from a cross between a high salt-tolerance indica variety, \\
\hline Keywords & $\begin{array}{l}\text { TCCP266, and a susceptible elite temperate-japonica Egyptian variety, Sakha102, were } \\
\text { produced. We performed QTL mapping for physiological traits related to rice salt- }\end{array}$ \\
\hline Quantitative Trait & $\begin{array}{l}\text { tolerance. Single plant analysis of each of the polymorphic marker was carried out using } \\
\text { randomly selected } 288 \text { F } 2 \text { individuals } 50 \text { polvmornhic markers covered four chromosomes }\end{array}$ \\
\hline $\begin{array}{l}\text { Loci (QTL), } \\
\text { Rice Salt Tolerance }\end{array}$ & of rice $(1,3,4$ and 9$)$. A total of 24 QTL were detected (LOD score $>2.0$ ), which were \\
\hline (Oryza sativa L.), & $\begin{array}{l}\text { distributed on the four chromosomes. The number of QTL was detected in non-saline (14) } \\
\text { and saline soil (10). Seven QTL for Na+ concentration were detected in leaves at }\end{array}$ \\
\hline Article Info & vegetative stage as well as leaves at reproductive stage with LOD score $>2.0$. These 7 QTL \\
\hline Accepted: & chromosome 4 and three in chromosome 3 . A total of 13 QTL were detected (LOD score > \\
\hline & 2.0) for $\mathrm{K}+$ concentration on chromosomes $1,3,4$ and 9 . LOD score ranged from 2.09 to \\
\hline $\begin{array}{l}\text { Available Online: } \\
10 \text { January } 2017\end{array}$ & $\begin{array}{l}4.54 \text { and the phenotypic variance explained by a single QTL (R2) ranged between } 5.3 \% \\
\text { and } 12.7 \% \text {. Four detected OTL controlling } \mathrm{Na} / \mathrm{K}+\text { ratio were distributed on two }\end{array}$ \\
\hline & $\begin{array}{l}\text { chromosomes } 4 \text { and } 9 \text { with LOD score range between } 2.55 \text { to } 3.95 \text { and a range of } \\
\text { phenotypic variance explained between } 7.4 \% \text { up to } 11.2 \% \text {. The detection of new QTLs } \\
\text { associated with salt tolerance will provide important information for the functional } \\
\text { analysis of rice salt tolerance. }\end{array}$ \\
\hline
\end{tabular}

\section{Introduction}

Rice is important crops used as the staple food of over half of the world's population and the increase rice grain production is the actual goal for today. One of the severe limitations to increase rice production is considered to soil salinity (Ali et al., 2014).

The study of morpho-physiological response to salinity is important with the standpoint of understanding the mechanisms of plant adaptation to stressful influences. The pivot to plant survival under salinity is preserving an ion balance in the cells (Das et al., 2015).

Tolerance to a biotic stresses is very complex at the whole plant and cellular levels (Munns and Tester, 2008, Grewal, 2010). Since salt tolerance has low heritability, phenotypic selection is difficult and progress through conventional breeding, although noticeable, 
has been slow. Conventional breeding will be enhanced greatly by biotechnological tools, allowing breeders to formulate more proficient breeding strategies (Collard and Mackill, 2007). There is still a gap between genomics and its application to breeding and although the possibilities are indefinite, a long way still needs to be accomplished (Xu et al., 2005). Recent advent of molecular markers, microsatellites or simple sequence repeats (SSRs) increased the hope to find out salt tolerant rice genotypes (Bhowmik et al., 2009).

Molecular marker technology has wide and diverse applications. With the availability of an array of molecular markers and genetic maps, Marker Assisted Selection (MAS) has become possible both for traits governed by major genes as well as for quantitative trait loci (QTL) (Francia et al., 2005). Usefulness of a given molecular marker is dependent on its capability in revealing polymorphisms allowing discrimination between alleles. The present investigation is an effort to map the QTLs controlling salt tolerance in rice at different growth stages using molecular marker systems such as Microsatellite Sites (SSR) which are highly polymorphic, codominant, simple, abundant and distributed throughout the entire rice genome.

\section{Materials and Methods}

\section{Plant materials}

Rice (oryza sativa L.) used population (TCCP266-1-2/Sakha 102) (Indica Tolerant variety/Japonica Sensitive variety) parents. The F2 seeds were grown, along with their respective parents, for 25 days after sowing and seedlings were transplanted in the research experimental field (Rice Research and Training Center, Egypt). After 25 days from transplanting, each individual F2 plant was further splitted into 3 parts. One for the vegetative stage screening, another tiller was taken for the reproductive stage screening, and the rest of the plant remained in the permanent experimental field for collecting leaf samples for DNA extraction.

\section{Lysimeter experiment}

The Lysimeter is concrete beds filled with soil to $100 \mathrm{~cm}$ depth in three layers: $60 \mathrm{~cm}$ clay at surface, $20 \mathrm{~cm}$ sand at the middle and $20 \mathrm{~cm}$ gravel at the bottom. The materials were grown in Lysimeter under level of salinity $6000 \mathrm{ppm}$ in addition to the control (Tap water).

\section{Vegetative and reproductive stages parameters}

Despite taking the general morphological parameters of the individual F2 plants, our main focus was to depend largely on the physiological parameters. A total of 12 different parameters indicating salinity tolerance in rice plants were analyzed, these included 6 parameters at vegetative stage and 6 at reproductive stage. The vegetative and reproductive stages parameters are three parameters analyzed in leaf and stem samples in each growth stage. These are more accurate and reliable $\mathrm{Na}^{+}, \mathrm{K}^{+}$concentration and $\mathrm{Na}^{+}$ $/ \mathrm{K}^{+}$ratio at vegetative and reproductive stages were determined both on leaves and stems.

\section{F2 population Genotyping}

\section{PCR analysis}

DNA from the $288 \mathrm{~F}_{2}$ plants was genotyped by using 68 SSR primer pairs polymorphic in the parental lines. The confirmed alleles were processed, analyzed and reviewed by exploiting the gene mapper software version 3.7. The banding pattern (Peaks) was scored using $\mathrm{A}, \mathrm{B}$ and $\mathrm{H}$ for parent 1 type (Sakha 102), parent 2 type (TCCP266-1-2) and heterozygous types, respectively. 


\section{Map construction}

Loci linkage was performed by using MAPMAKER version $3.0 \mathrm{~b}$ (Lander et al., 1987). Kosambi (1944) function was used to convert the recombination frequency to genetic distance in centimorgans (cM). Twopoint analysis was carried out on F2 data to identify linkage group at a LOD score of 2.0. Data were put in as $\mathrm{A}, \mathrm{B}$ and $\mathrm{H}$ to mark genotypes of parent $\mathrm{A}$; parent $\mathrm{B}$, and heterozygotes, respectively, for co-dominant marker, and ' - ' = missing data at individual locus.

The obtained order was then analyzed further using a three-Point linkage analysis 'Ripple' command. Other markers were added using the 'Try' command and fine-tuned using again the 'Ripple' command. The 'Ripple' command was conducted to assign exact positions to markers. Both chromosome assignment and centromere localization were determined by comparing the map to the previously published ones (Roder et al., 1998).

\section{QTL identification}

Using MAPMAKER/QTL version $1.1 \mathrm{~b}$ (Lander et al., 1987), which perform simple interval mapping using the MAPMAKER result files as a raw data files. A widely used algorithm for QTL detection and mapping is that implemented in the MAPMAKER/QTL software package (Lincoln and Lander, 1992). Their method is based on LOD scores computed at regular incremental values throughout the genome. Lander and Botstein (1989), suggest that a typical LOD threshold should be between 2 and 3 to ensure an overall false positive rate of $5 \%$ for QTL detection. The software can give a graphical display of the LOD score and confidence interval of possible QTL positions along the chromosomes.

\section{Results and Discussions}

Genotyping of the mapping population using ssr markers

While applying the interval mapping approach for detecting QTLs, presence of polymorphic markers at fixed intervals is a pre-requisite. Out of the 275 SSR primers screened, 68 primers selected from 187 primers were showing polymorphism between the parental lines Sakha 102 and TCCP266, which located in Chr. 1, 3, 4 and 9.

Some of these markers were clustered at the same position, limiting their usefulness in the mapping process, since one of the points in our target is to focus less than $10 \mathrm{cM}$ on each chromosome, so 11 SSR markers have been eliminated from the 68 polymorphic ones to be in the final 57 polymorphic mapped ones. Their physical location on the 4 rice chromosomes was determined with the help of the rice genome sequence data.

The first step was accurate placement of the 57 markers polymorphic between the two parents on the integrated genetic/physical map of the rice genome rather than their previously reported genetic locations.

\section{Single plant analysis of the $F_{2}$ mapping population}

Single plant analysis of each of the polymorphic marker was carried out using randomly selected $288 \mathrm{~F}_{2}$ individuals.

After PCR amplification with SSR primers, the PCR products were analyezed (Applied Biosystems Prism ${ }^{\circledR} 3130 x 1$ Genetic Analyzer) to detect the peaks of the parental lines as well their $\mathrm{F}_{2}$ progeny depending upon the size difference in the alleles Fig.1. 
Co-segregation Analysis and QTL identification

\section{Construction of the genetic map}

These differences in the size of the mapping populations may depend on the genome size of the organism, the generation of mapping population and the nature of the inheritance of the trait under study. 57 different polymorphic SSR markers were used to construct the linkage map of F2:3 families. A population of 288 F2 plants is certainly perfect plant numbers that have been analyzed in comparable studies. Out of 57 markers analyzed, 7 SSR markers were behaving abnormally showing high level of distorted segregation using various MAPMAKER commands. It proved difficult to place them in the expected map positions, giving upnormal recombination values, and furthermore, they didn't fit in with the expected Mendelian ratio (1:2:1) as revealed from the primary data analysis using the Carthagene1. Those markers have been eliminated from the genetic map constructed for the present mapping population. The remaining 50 polymorphic markers covered the four chromosomes of rice. The order of the markers in each chromosome was mostly consistent with the Cornel II genetic map 2001 (The map reference). The distribution of the mapped SSR markers coverage the four chromosome 1, 3, 4 and 9 rice genome of the two parents Sakha 102 and TCCP266, percent of covering per each chromosome, chromosome length (cM) and average distance between markers in each chromosome (cM), are shown in Table 1.

The distribution of the 50 markers loci across the 4 chromosomes indicated that there are more markers identified on chromosome 1 and chromosome 3 . The chromosome with the fewest markers is chromosomes 9. This result is in harmony with Cornel II genetic map
2001 (The map reference) and the genetic map obtained by Ammar, 2004 and El-Refaee (2009).

In this mapping population the marker distribution was relatively adequate and few clusters of tightly linked loci were revealed, as all SSR marker locations were known and the markers were selected to avoid closely linked multiple loci. Map locations of all markers were comparable to that reported for the Cornel II genetic map 2001 (The map reference). The genetic map results as a prefile for the QTL analysis using PLABQTL.

\section{QTL identification and mapping}

\section{Chromosome wise distribution of detected QTL}

Genotyping data of the F2 population were combined with the phenotypic mean values of the corresponding F2 families in order to identify and map QTL, following PLABQTL software (Urz and Melchinger, 1996).

The distribution on four rice chromosomes of QTL detected both in saline and non saline conditions for all considered traits and different measured parameters of salt tolerance (LOD score > 2.0) are shown Table 2.

When considering both environments, a total of 24 QTL were detected (LOD score > 2.0), which were distributed on four chromosomes. The number of QTL was detected in nonsaline (14) and saline soil (10).

\section{QTL for $\mathrm{Na}+$ concentration in leaf and stem tissues}

Salt tolerant plants minimize $\mathrm{Na}+$ toxicity by maintaining a low $\mathrm{Na}+$ concentration in the active leaf tissues. This could be achieved by selective absorption, storing excess $\mathrm{Na}+$ in the 
vacuoles or pump it out of the cell. The QTL for $\mathrm{Na}+$ concentration in leaves and stems under the two different saline conditions were shown in Table 2.

For vegetative stage in leaf samples, $(\mathrm{Na}+$ LV) one QTL was found (LOD score > 2.0), in saline conditions. The allele increasing the trait for the single QTL detected in saline condition (QTL 1) was contributed by TCCP266. Position of QTL 1 (chr.3, $150 \mathrm{cM}$ ) suggested the presence of a locus with the same type of gene action exerting a relevant effect on $\mathrm{Na}+$ concentration in leaves at vegetative stage in both environmental conditions. The increasing allele was contributed in both environments by TCCP266 (salt tolerant parent), suggesting the same type of gene action in both environments. The QTL 1 was detected in the interval RM571-RM514, 9.1 cM from the left marker; it has a LOD score of 2.19. At vegetative stage in stem samples, $(\mathrm{Na}+\mathrm{SV})$ no QTL were detected.

On reproductive stage in leaf samples, $(\mathrm{Na}+$ LR) two QTL were detected with LOD score $>2.05$, one QTL was detected in non-saline and one in saline conditions. The first QTL in non-saline was detected in the interval RM282-RM156, $29.3 \mathrm{cM}$ from the left marker; it has a LOD score of 2.21.

At the reproductive stage in stem samples, (Na+ SR) four QTL were found, two in nonsaline and two in saline conditions. $\mathrm{R} 2$ values for Na SR QTL ranged from 5.9\% (QTL 5 and 7) to $7.1 \%$ (QTL 4). Position of QTL 4 and QTL 6 (chr.1, $282 \mathrm{cM}$ ) suggests the presence of a locus with the same type of gene action exerting a relevant effect on $\mathrm{Na}+$ concentration in stem at reproductive stage in both environmental conditions. The increasing allele was contributed in both environments by TCCP266 (salinity tolerant parent), suggesting the same type of gene action in both environments. The QTL 5 and 7 were detected in the interval RM307RM335, $9 \mathrm{cM}$ from the right marker; they had a LOD score of 2.04 and 2.05, respectively. The additive effects for the common detected QTL between the saline and non-saline conditions that controlling $\mathrm{Na}+$ concentration in both two different growth stages in the plant were derived from the salt tolerant rice variety TCCP266.

In conclusion, 7 QTL for $\mathrm{Na}+$ concentration were detected in leaves at vegetative stage and stem at reproductive stage, while no QTL were detected in stem at vegetative stage as well as leaves at reproductive stage with LOD score >2.0. These 7 QTL are localized on chromosomes 1, 3 and 4. Two QTL on chromosome 1, two on chromosome 4 and three in chromosome 3 . These QTL could be of a practical importance. They may contain constitutive expressing salt stress responsive genes under two different soil conditions, which may control other down regulated genes. QTL related to salt tolerance parameters were identified in other experiments, using different populations, for instance, Gregorio, (1997) used simple mapping in F8 RIL population derived from Pokkali/IR29, and identified 4 QTL for $\mathrm{Na}+$ concentration, one on chromosome 1 , two on chromosome 3 and one on chromosome 10, with a range of phenotypic variation explained between $16 \%$ up to $64.6 \%$. Our results were in agreement with this except for chromosome 10; this could be partially due the use of TCCP266 (tolerant parent for salinity) that operates by different mechanisms. The results were in agreement with those of Koyama et al., (2001), they identified 3 QTL on chromosomes 4, 6 and 7. Also in agreement with those of Ammar (2004), who identified 11 QTL for $\mathrm{Na}+$ concentration, one on chromosome 1 , three on chromosome 2, four on chromosome 3 and three on chromosome 4. Comparing and /or 
combining results from different QTL experiments is difficult due to differences in genomic structures and in the materials utilized. However, the fact that some of the QTL we have identified map in positions similar to those of QTL already described in the literature is an important finding which requires further considerations.

\section{QTL for $\mathrm{K}+$ concentration in leaf and stem tissues}

Considering $\mathrm{K}+$ concentration, that was probably the key factor in salt tolerance for the materials we analyzed. Its elevated concentration under the salt stress will allow plants to maintain a low $\mathrm{Na}+/ \mathrm{K}+$ ratio and enhance plant survival. The QTL for $\mathrm{K}+$ concentration in leaves and stems under the two different saline conditions are showed in Appendix Table 16.

At the vegetative stage in leaf samples, $(\mathrm{K}+$ LV) two QTL were found, one in non-saline and the other in saline conditions. Alleles significantly increasing the trait in both of the two environments were contributed by Sakha 102 (QTL 8 and QTL 9). R2 value for K LV QTL 8 (chr.3) was 10.4, while it was 6.3 for QTL 9 (chr.3). The increasing allele was contributed in both environments by Sakha 102 , suggesting the same type of gene action in both environments. The QTL 8 with a LOD score of 3.65 was localized in the interval RM570-RM85, $1.9 \mathrm{cM}$ from the left marker. While, QTL 9 with a LOD score of 2.17 was detected in the interval RM570-RM85, 13.9 $\mathrm{cM}$ from the left marker.

Two QTL were detected for potassium concentration in the stem at vegetative stage, one in non-saline condition and one in saline condition. QTL detected in saline environment, alleles significantly increasing the trait were contributed by both parents TCCP266 (QTL 10) and Sakha 102 (QTL 11). QTL10 was located on chromosome 1, between RM493 and RM24 with distance of $1.4 \mathrm{cM}$ from RM24 and a LOD score of 3.52. Phenotypic variance explained by this QTL was $5.3 \%$ due to additive effect. For QTL11, located on chromosome 9, between RM257 and RM242 with distance of $2.0 \mathrm{cM}$ from RM257 had a LOD score of 3.09 and the phenotypic variance explained was $7.0 \%$ due to additive effect.

At the reproductive stage in leaf samples $(\mathrm{K}+\mathrm{LR})$, six QTL were found in non-saline environment. Alleles significantly increasing the trait in non- saline environment were contributed by both Sakha 102 (QTL 12 and 16) and TCCP266 (QTL 13, 15 and 17). No significant additive effect was observed for QTL 14.

Table.1 Distribution of polymorphic microsatellite markers coverage the four rice chromosomes of the two parents Sakha 102 and TCCP266

\begin{tabular}{|c|c|c|c|c|c|}
\hline $\begin{array}{c}\text { Chromosom } \\
\text { e No. }\end{array}$ & $\begin{array}{c}\text { No. of selected } \\
\text { SSR markers }\end{array}$ & $\begin{array}{c}\text { No. of polymorphic } \\
\text { SSR markers }\end{array}$ & $\begin{array}{c}\text { No. of mapped } \\
\text { SSR markers }\end{array}$ & $\begin{array}{c}\text { Size } \\
(\mathrm{cM})\end{array}$ & $\begin{array}{c}\mathrm{cM} / \\
\text { Marker }\end{array}$ \\
\hline Chr.1 & 35 & 27 & 20 & 326.80 & 16.34 \\
\hline Chr.3 & 34 & 20 & 12 & 215.60 & 17.97 \\
\hline Chr.4 & 23 & 15 & 11 & 285.10 & 25.92 \\
\hline Chr.9 & 15 & 10 & 7 & 148.20 & 21.17 \\
\hline
\end{tabular}


Table.2 List of total detected QTL with LOD score $>2.0$.

\begin{tabular}{|c|c|c|c|c|c|c|c|c|c|c|c|c|}
\hline QTL \# & Trait $^{\mathbf{a}}$ & Env ${ }^{b}$ & Chr & QTL & NML $^{c}$ & $\mathbf{N M R}^{\mathrm{c}}$ & Marker interval & Supporting & LOD & $\mathbf{R}^{\wedge^{2}}$ & Additive & Std. \\
\hline 1 & $\mathrm{Na}^{+} \mathrm{LV}$ & $\mathrm{S}$ & 3 & 150 & 9.1 & 12.2 & RM571-RM514 & $136-164$ & 2.19 & 6.3 & 2.304 & $0.912 *$ \\
\hline 2 & $\mathrm{Na}^{+} \mathrm{LR}$ & NS & 3 & 78 & 29.3 & 1.1 & RM282-RM156 & $62-96$ & 2.21 & 6.4 & -1.504 & $0.469 * *$ \\
\hline 3 & $\mathrm{Na}^{+} \mathrm{LR}$ & $\mathrm{S}$ & 3 & 78 & 29.3 & 1.1 & RM282-RM156 & $62-96$ & 2.15 & 6.2 & -2.91 & $0.935^{* *}$ \\
\hline 4 & $\mathrm{Na}^{+} \mathrm{SR}$ & NS & 1 & 282 & 17.4 & 1.8 & RM472-RM104 & $270-290$ & 2.45 & 7.1 & 0.012 & 0.71 \\
\hline 5 & $\mathrm{Na}^{+} \mathrm{SR}$ & NS & 4 & 64 & 13.1 & 9 & RM307-RM335 & $50-84$ & 2.04 & 5.9 & 0.137 & 0.71 \\
\hline 6 & $\mathrm{Na}^{+} \mathrm{SR}$ & $\mathrm{S}$ & 1 & 282 & 17.4 & 1.8 & RM472-RM104 & $270-290$ & 2.41 & 7 & -0.027 & 1.42 \\
\hline 7 & $\mathrm{Na}^{+} \mathrm{SR}$ & $S$ & 4 & 64 & 13.1 & 9 & RM307-RM335 & $50-84$ & 2.05 & 5.9 & 0.351 & 1.41 \\
\hline 8 & $\mathrm{~K}^{+} \mathrm{LV}$ & NS & 3 & 186 & 1.9 & 29.6 & RM570-RM85 & 176-198 & 3.65 & 10.4 & -0.372 & $0.145^{*}$ \\
\hline 9 & $\mathrm{~K}^{+} \mathrm{LV}$ & $\mathrm{S}$ & 3 & 198 & 13.9 & 17.6 & RM570-RM85 & $170-212$ & 2.17 & 6.3 & -0.212 & 0.14 \\
\hline 10 & $\mathrm{~K}^{+} \mathrm{SV}$ & $S$ & 1 & 158 & 9.6 & 1.4 & RM493-RM24 & $150-180$ & 3.52 & 5.3 & 0.312 & $0.111 * *$ \\
\hline 11 & $\mathrm{~K}^{+} \mathrm{SV}$ & $\mathrm{S}$ & 9 & 122 & 2 & 7 & RM257-RM242 & $108-130$ & 3.09 & 7 & -0.422 & $0.129 * *$ \\
\hline 12 & $\mathrm{~K}^{+} \mathrm{LR}$ & NS & 1 & 236 & 2.7 & 4.4 & RM302-RM486 & $228-240$ & 4.54 & 12.7 & -0.921 & $0.164 * *$ \\
\hline 13 & $\mathrm{~K}^{+} \mathrm{LR}$ & NS & 1 & 260 & 5.8 & 4.6 & RM315-RM472 & $254-278$ & 3.22 & 9.2 & 0.653 & 0.155 ** \\
\hline 14 & $\mathrm{~K}^{+} \mathrm{LR}$ & NS & 3 & 10 & 10 & 1.3 & RM132-RM22 & $6-12$ & 3.48 & 10.1 & -0.136 & 0.1 \\
\hline 15 & $\mathrm{~K}^{+} \mathrm{LR}$ & NS & 3 & 90 & 10.9 & 33.1 & RM156-RM293 & $72-104$ & 4.43 & 12.3 & 0.447 & $0.122 * *$ \\
\hline 16 & $\mathrm{~K}^{+} \mathrm{LR}$ & NS & 3 & 204 & 19.9 & 11.6 & RM570-RM85 & 194-214 & 4.38 & 12.4 & -0.449 & $0.113 * *$ \\
\hline 17 & $\mathrm{~K}^{+} \mathrm{LR}$ & NS & 4 & 284 & 33.8 & 1.1 & RM280-RM127 & $270-284$ & 3.63 & 12.7 & 0.343 & $0.091 * *$ \\
\hline 18 & $\mathrm{~K}^{+} \mathrm{SR}$ & NS & 1 & 18 & 18 & 0.6 & RM428-RM495 & $2-20$ & 2.8 & 9.5 & -1.45 & 0.431 ** \\
\hline 19 & $\mathrm{~K}^{+} \mathrm{SR}$ & NS & 1 & 72 & 23.4 & 0.7 & RM272-RM259 & $66-82$ & 3.76 & 10.6 & 1.85 & $0.408 * *$ \\
\hline 20 & $\mathrm{~K}^{+} \mathrm{SR}$ & NS & 9 & 76 & 0.3 & 44 & RM105-RM257 & $56-90$ & 2.09 & 6.1 & -0.136 & 0.36 \\
\hline 21 & $\mathrm{Na}^{+} / \mathrm{K}^{+} \mathrm{SV}$ & NS & 4 & 168 & 12 & 0.8 & RM252-RM241 & $162-182$ & 3 & 8.5 & 0.008 & $0.002 * *$ \\
\hline 22 & $\mathrm{Na}^{+} / \mathrm{K}^{+} \mathrm{SV}$ & $\mathrm{S}$ & 9 & 128 & 8 & 1 & RM257-RM242 & $120-136$ & 3.3 & 9.7 & 0.501 & $0.142 * *$ \\
\hline 23 & $\mathrm{Na}^{+} / \mathrm{K}^{+} \mathrm{LR}$ & $S$ & 4 & 64 & 13.1 & 9 & RM307-RM335 & $54-74$ & 3.95 & 11.2 & -0.194 & 0.24 \\
\hline 24 & $\mathrm{Na}^{+} / \mathrm{K}^{+} \mathrm{LR}$ & $\mathrm{S}$ & 9 & 130 & 1 & 7.4 & RM242-RM201 & $120-138$ & 2.55 & 7.4 & 0.872 & $0.251 * *$ \\
\hline
\end{tabular}

${ }^{\mathrm{a}}$ See abbreviation

${ }^{\mathrm{d}}$ Support interval is the 1-LOD-unit-down support interval

${ }^{\mathrm{e}} \mathrm{R} 2$ (coefficient of determination) represents the proportion of variability in the phenotype that may be attributed to combination of

${ }^{\mathrm{f}}$ Stars indicate significance level $(*: p<0.05 ; * *: p<0.01)$

$*$ Detected QTL with LOD score $<2.5$ and $>2.0$ 
Fig.1 Fragments analysis using Genemapper software v3.7 of polymorphic microsatellite markers in two parental lines and F2 offspring, amplified with the SSR markers loci RM85(black color) and RM143(green color).The peaks represent fragments of different alleles, A allele=P1(Sakha 102 ), B allele=P2(TCCP266) and $\mathrm{H}$ allele = hetero-zygot, whereas the vertical scale indicates peaks height and the horizontal scale indicates fragment sizes in base pairs

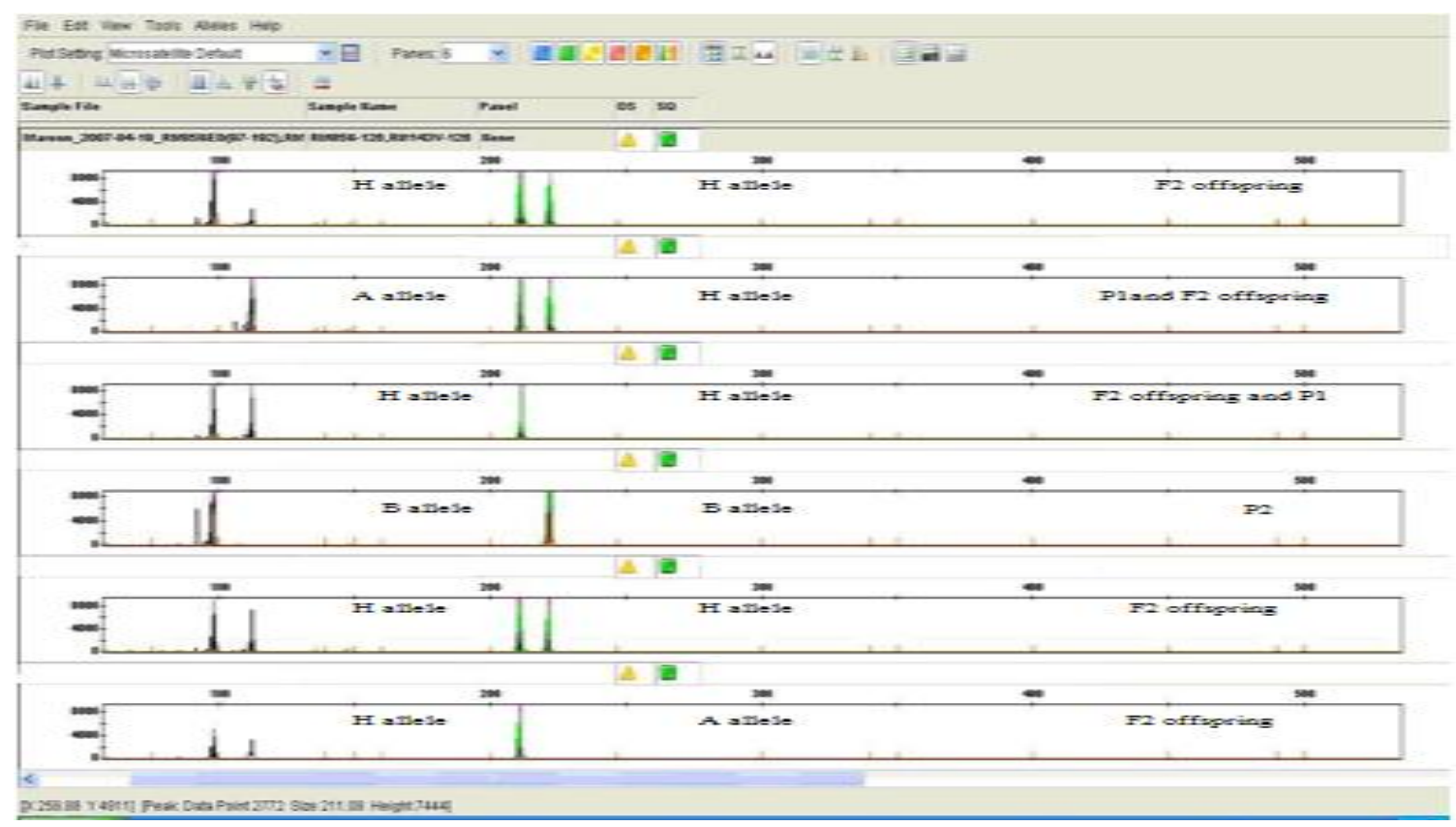

Fig.2 Genetic linkage map representing the 4 rice chromosomes obtained, analyzing a population of 288 F2 plants from the cross Sakha 102 (temperate japonica spp. sensitive) x TCCP266 (indica spp. tolerant).
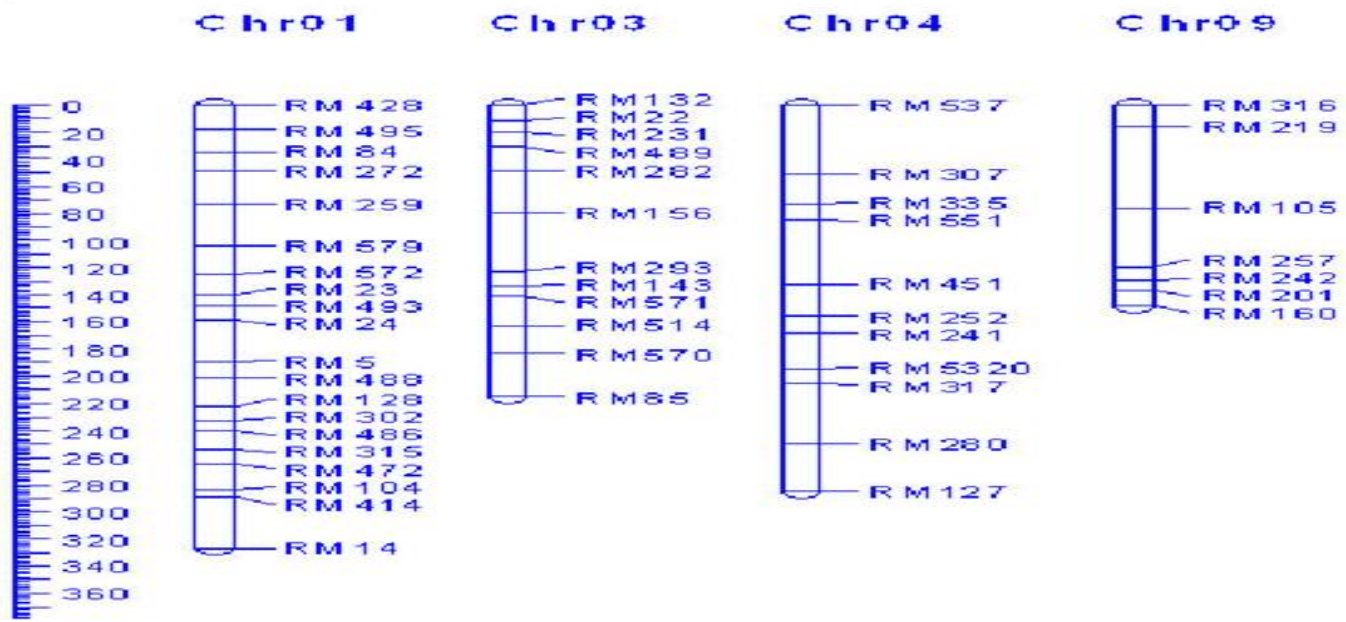

For potassium concentration in stem samples at reproductive stage $\left(\mathrm{K}^{+} \mathrm{SR}\right)$, three QTL detected in non-saline environment was shown. Alleles significantly increasing the trait in non saline environment were contributed by both Sakha 102 (QTL 18) and
TCCP266 (QTL 19. the three QTL (QTL 18, 19, and 20) localized on chromosomes 1 and 9 respectively. R2 values for $\mathrm{K}+\mathrm{SR}$ QTL ranged from $6.1 \%$ (QTL 20) to $10.6 \%$ (QTL 19). 
From the above results, a total of 13 QTL were detected (LOD score > 2.0) for $\mathrm{K}+$ concentration on chromosomes 1, 3, 4 and 9 . LOD score ranged from 2.09 to 4.54 and the phenotypic variance explained by a single QTL (R2) ranged between 5.3\% and $12.7 \%$. These results, along with those of Flower et al., (2000), Ren et al., (2005) and Ammar (2004), suggested that mechanisms and subsequently the gene(s) responsible for $\mathrm{K}+$ concentration and transport are quite different from those for $\mathrm{Na}+$. This was also conducted from the correlation coefficient results described in the above sections in correspondence with that of Ammar (2004) and El- Refaee (2009).

\section{QTL for $\mathrm{Na}+/ \mathrm{K}+$ ratio in leaf and stem tissues}

Since a lower $\mathrm{Na}+\mathrm{K}+$ ratio is considered a good parameter for plants tolerate to salt stress, it is important to identify QTL determining $\mathrm{Na}+\mathrm{K}+$ ratio. The QTL for $\mathrm{Na}+\mathrm{K}+$ ratio in leaves and stems under the two different saline conditions are shown in Appendix Table 2. At vegetative stage for $\mathrm{Na}+/ \mathrm{K}+$ ratio in leaves, $(\mathrm{Na}+\mathrm{K}+\mathrm{LV})$ no QTL were detected.

For $\mathrm{Na}+/ \mathrm{K}+$ ratio in stem at vegetative stage, two QTL were found, one in non saline and one in saline conditions. Alleles significantly increasing the trait in non saline environment were contributed by TCCP266 (QTL 21), whereas alleles significantly increasing in saline environment were contributed by Sakha 102 (QTL 22). R2 values ranged from 8.5\% (QTL 21) to 9.7\% (QTL 22). The QTL 21 located on chromosomes 4 which located at $0.8 \mathrm{cM}$ from RM241. QTL 22 located on chromosome 9 between RM257 and RM242 with distance of $1.0 \mathrm{cM}$ from RM242 and a LOD score of 3.3 .

Regarding to $\mathrm{Na}+\mathrm{K}+$ ratio in leaves at reproductive stage, two QTL were detected.
All the detected QTL were found in saline condition. Alleles significantly increasing the trait were contributed by TCCP266 (QTL 24), whereas no significant additive effect was observed for QTL 23. The two QTL (23, and 24) located on chromosomes 4 and 9, respectively. The QTL 23 was located on chromosome 4, in the interval RM 307RM335, with genetic distance of $9.0 \mathrm{cM}$ form RM 335. This QTL has a LOD score of 3.95 and explained 11.2 of phenotypic variance. The QTL24 was located on chromosome 9, in the interval RM242-RM201, with genetic distance of $1.0 \mathrm{cM}$ from left marker. This QTL has a LOD score of 2.55 and explained $7.4 \%$ of phenotypic variance. For $\mathrm{Na}+\mathrm{K}+$ ratio in stem at reproductive stage, no QTL were detected.

The 4 detected QTL controlling $\mathrm{Na}+\mathrm{K}+$ ratio were distributed on two chromosomes 4 and 9 with LOD score range between 2.55 to 3.95 and a range of phenotypic variance explained between $7.4 \%$ up to $11.2 \%$. Our results are in partial agreement with those of Gregorio, (1997), who detected 3 QTL on chromosomes 1, 10 and 12. Also in partial agreement with those of Ammar (2004), who detected 12 QTL, 1, 3, 3, 1, 1, 2, and 1 on chromosome 1, $2,3,4,5,8$, and 11, respectively. As discussed earlier, this may be partially due to the different genetic background since Gregorio, (1997) used (Pokkali/IR29), Ammar (2004), used Nona Bokra derived variety CSR27 compared to our TCCP266-12. and El-Refaee (2009) used (Giza 177/ TCCP 266-1-2).

\section{References}

Ali, M.N., L. Yeasmin, S. Gantait, R. Goswami and S. Chakraborty. 2014. Screening of rice landraces for salinity tolerance at seedling stage through morphological and molecular markers. Physiol. Mol. Biol. Plants, 20: 411423.

Ammar, M.H.M. 2004. Molecular mapping of salt 
tolerance in rice. $\mathrm{Ph}$. D. Thesis, Indian Agricultural Research Institute, New Delhi, India.

Bhowmik, K.S., Soubir, T., Mirza, M.I., Ayesha, S., Sharmin, S. and M.D. Shahidul Haque. 2009. Phenotypic and genotypic screening of rice genotypes at seedling stage for salt tolerance. African J. Biotechnol., Vol. 8 (23), 6490-6494.

Collard B.C.Y. and D.J. Mackill. 2007. Markerassisted selection: an approach for precision plant breeding in the 21st century. Phil. Trans. Royal Soc. B Rev.

Das, P., K.K. Nutan, S.L. Singla-Pareek and A. Pareek. 2015. Understanding salinity responses and adopting "omics-based" approaches to generate salinity tolerant cultivars of rice. Frontiers Plant Sci., 6: 712712.

El- Refaee, Y.Z. 2009. Identification of Quantitative Trait Loci (QTL) for salt tolerance in rice (oryza sativa L.) $\mathrm{Ph}$. D. Thesis, Sant Anna School of advanced studies Uni., Italy. 198p.

Flower, T.J., M.L. Koyama, S.A. Flowers, C. Sudhakar, K.P. Singh and A.R. Yeo. 2000. QTL: their place in engineering tolerance of rice to salinity. J. Exp. Bot., 51(342): 99-106.

Francia, E., G. Tacconi, C. Crosatti, D. Barabaschi, D. Bulgarelli, E. Dall'Aglio and G. Vale`. 2005. Marker assisted selection in crop plants. Plant Cell Tiss. Org. Cult., 82: 317-342.

Gregorio, G.B. 1997. Tagging salinity tolerance genes in rice using amplified fragment length polymorphism (AFLP. PhD. thesis, University of the Philippines, Los Baños.; 118 p.

Grewal, H.S. 2010. Water uptake, water use efficiency, plant growth and ionic balance of wheat, barley, canola and chickpea plants on a sodic vertosol with variable subsoil $\mathrm{NaCl}$ salinity. Agric. Water Manage., 97(1): 148156.

Kosambi, D. D. 1944. The estimation of map distances from recombination values. Ann. Eugen., 12: 172-175.

Koyama, M.L., Levesley, A., Koebner, R.M., Flowers, T.J. and Yeo, A.R. 2001. Quantitative trait loci for component physiological traits determining salt tolerance in rice. Plant Physiol., 125: 406-422.

Lander, E., P. Green, J. Abrahamson, A. Barlow, M. J. Daly, S. E. Lincoln and L. Newburg. 1987. MAPMAKER: An interactive computer package for constructing primary genetic linkage maps of experimental and natural population. Genomics 1: 174-181.

Lander, E.S. and D. Bostein. 1989. Mapping Mendelian factors underlying quantitative traits using RFLP linkage maps. Genetics, 121: 185-199.

Lincoln, S. and E. Lander. 1992. Systematic detection errors in genetic linkage data. Genomics, 14: 604-610.

Munns, R. and Tester, M. 2008. Mechanisms of salinity tolerance. Ann. Rev. Plant Biol., 59: 651-81.

Ren, Z.H., Gao, J.P., Li, L.G., Cai, X.L., Huang, W., Chao, D.Y., Zhu, M.Z., Wang, Z.Y., Luan, S. and Lin, H.X. 2005. A rice quantitative trait locus for salt tolerance encodes a sodium transporter. Nat. Genet., 37: 1141-1146.

Roder, M. S., V. Korzun, B. S. Gill and M. W. Ganal. 1998. The physical mapping of microsatellite markers in wheat. Genome.

Urz, H.F., and A.E. Melchinger. 1996. PLABQTL: a program for composite interval mapping of QTL. J. Quant. Trait Loci, 2: 1-5.

Xu, Y., S.R. McCouch and Q. Zhang. 2005. How can we use genomics to improve cereals with rice as a reference genome? Plant Mol. Biol., 59: 7-26.

\section{How to cite this article:}

Aysam M. Fayed and Mona A. Farid. 2017. Mapping of Quantitative Trait Loci (QTL) for Na+ and $\mathrm{K}+$ Uptake Controlling Rice Salt Tolerance (Oryza sativa L.). Int.J.Curr.Microbiol.App.Sci. 6(1): 462-471. doi: http://dx.doi.org/10.20546/ijcmas.2017.601.054 